\title{
MOTION OF SOURCE IMAGE IN CHANG-REFSDAL LENS
}

\author{
E. V. Fedorova, V. I. Zhdanov, A. N. Alexandrov \\ Taras Shevchenko National University of Kyiv, Astronomical Observatory \\ 3, Observatorna Str., Kyiv, 03053, Ukraine \\ (Received August 5, 2002; received in final form September 11, 2002)
}

\begin{abstract}
We present the image centroid (IC) trajectories in case of a distant source microlensed by a point mass in the presence of an external shear. We consider point sources and extended sources with uniform and Gaussian brightness distribution. The source moves uniformly with respect to the lens.

Key words: gravitational lenses, astrometric microlensing.
\end{abstract}

PACS number(s): 98.62.Sb, 95.30.Sf

Chang and Refsdal [1,2] proposed a simple gravitational lens model with the single star and external shear of the foreground galaxy, distorting image of a distant object. In this work we study the image centroid (IC) motion in this microlensing process. This problem is of increasing interest due to microarcsecond astrometry progress [3, 4], in particular, due to the forthcoming Space Interferometer Mission [4]. Observations of a positional IC shifts could be successfully combined with a traditional light curves monitoring, provided necessary accuracy of positioning is reached. Theoretical aspects of such an "astrometrical microlensing" have been discussed concerning our Galaxy and for extragalactic gravitational lens systems [3, 4, 9].

The lens equation in Chang-Refsdal model is $[1,2]$ :

$$
\mathbf{Y}=A \mathbf{X}-R_{\mathrm{E}}^{2} \frac{\mathbf{X}-\mathbf{X}_{g}}{\left|\mathbf{X}-\mathbf{X}_{g}\right|^{2}}, \quad A=\left(\begin{array}{cc}
1-\gamma & 0 \\
0 & 1+\gamma
\end{array}\right)
$$

$\mathbf{X}, \mathbf{X}_{g}$ and $\mathbf{Y}$ are two-dimensional vectors of microlensed image, microlens and unperturbed source position, respectively, on a celectial sphere in the source frame; $R_{\mathrm{E}}$ is Einstein ring radius [1], $\gamma$ is the external shear. In this paper we confine ourselves to the subcritical $(\gamma<1)$ case. Further, we consider the source in its rest frame with the brightness centre at the origin, whereas the lens moves uniformly with respect to this frame. We compute the position of IC of the point source by the method of Witt $[6,7]$ and Lewis et al. [5]. For extended sources we can represent the IC position by means of explicit integrals [8-10], which is essentially the ray-shooting method [1].

Here we present some of our results in Figs. 1a-1h; every figure shows the IC trajectories in the source rest frame and brightness curves (below) for the source trajectory represented at the right upper corner in the lens rest frame. We consider three types of the source: the point source, the source with gaussian brightness distributions and the source in the form of a uniform circle. The size in case of any extended source is $L=0.1 R_{\mathrm{E}}$. The figures show the observable IC trajectory with respect to the source (above) and light curve (bottom); $p$ is the impact parameter, $\beta$ is the angle between the direc- tion of the source motion and the abscissa axis. Caustic and source track (in the lens rest frame) is shown in the upper right corner. The numbers near the curves signify corresponding points in source and lens planes.

The form of the IC trajectory appears to be significantly dependent upon the location of source track relatively to the caustic and the size of the source. Source brightness distribution affects the IC trajectory form too, but less significantly. Note that in caustic crossing events the IC trajectory is very sensitive to the source parameters, so this trajectory may be an important source of astrophysical information.
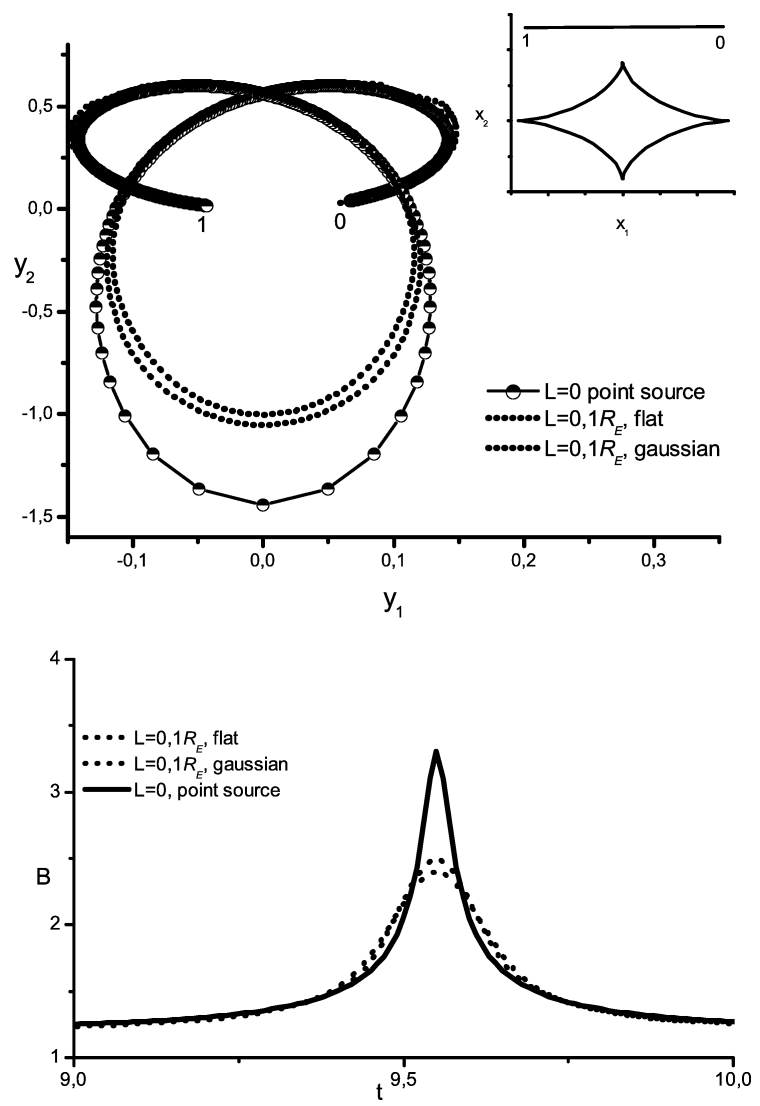

a) 

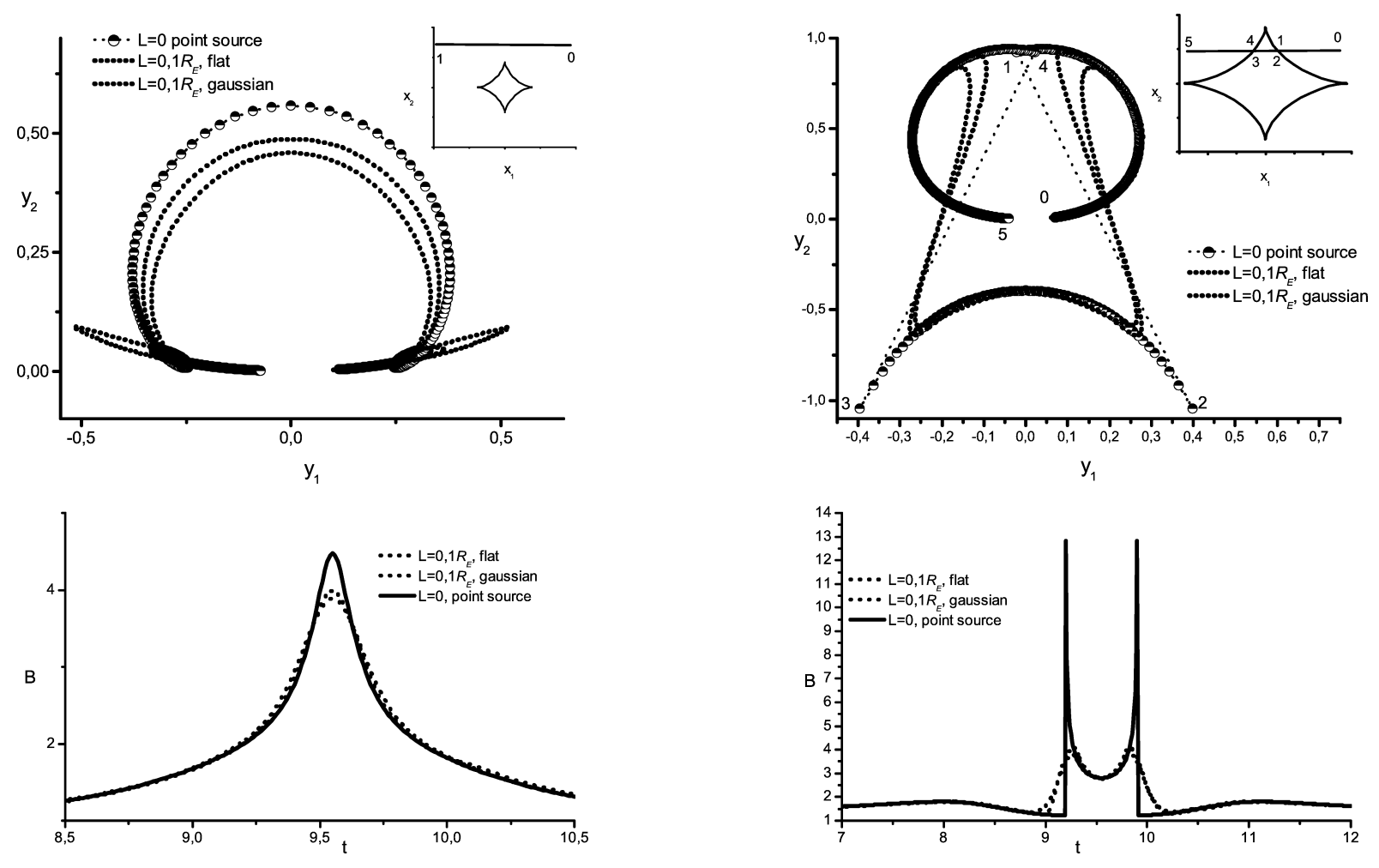

b)

d)
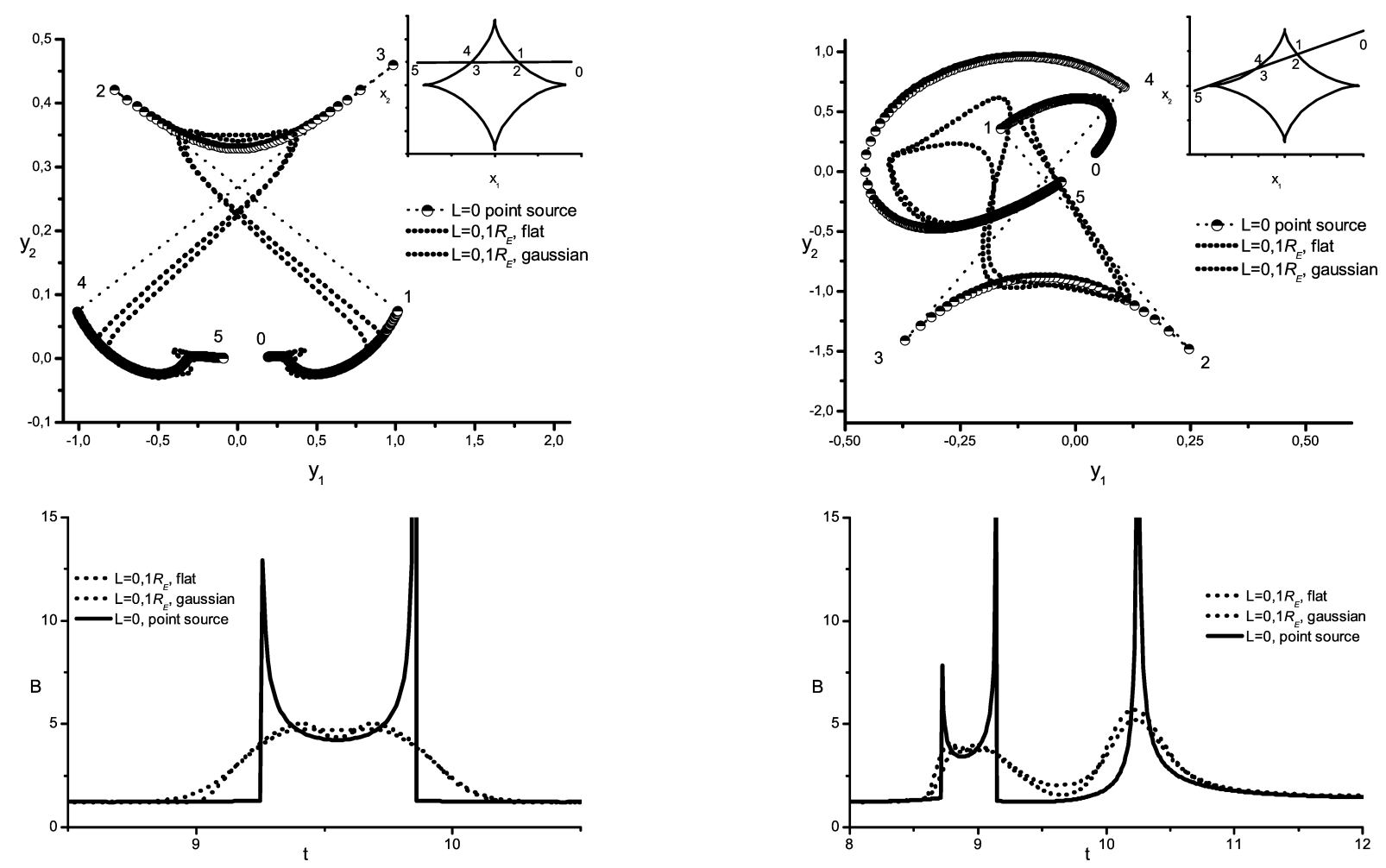

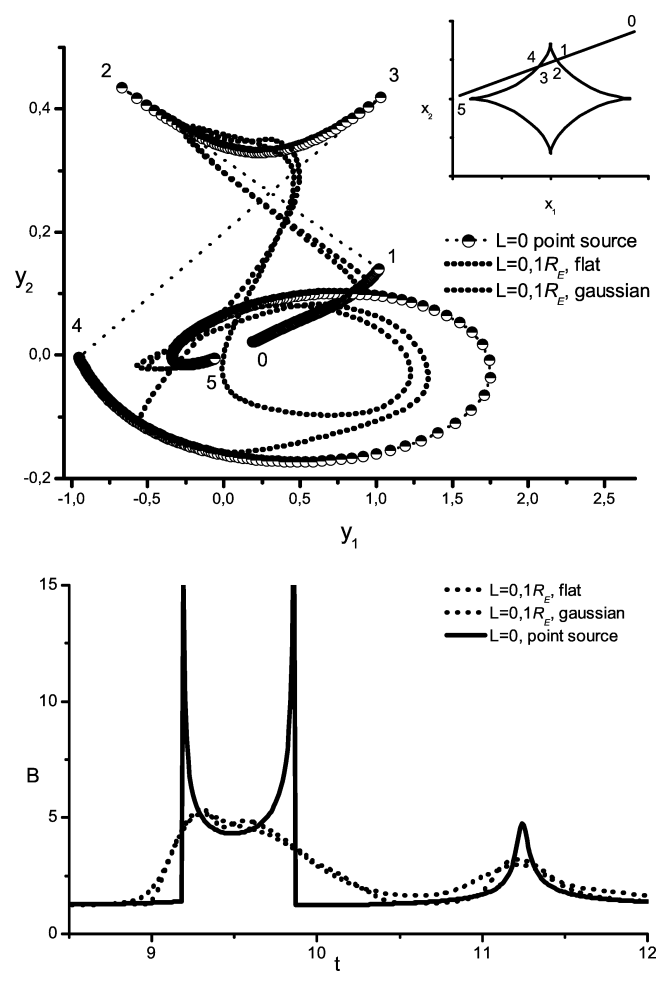

f)
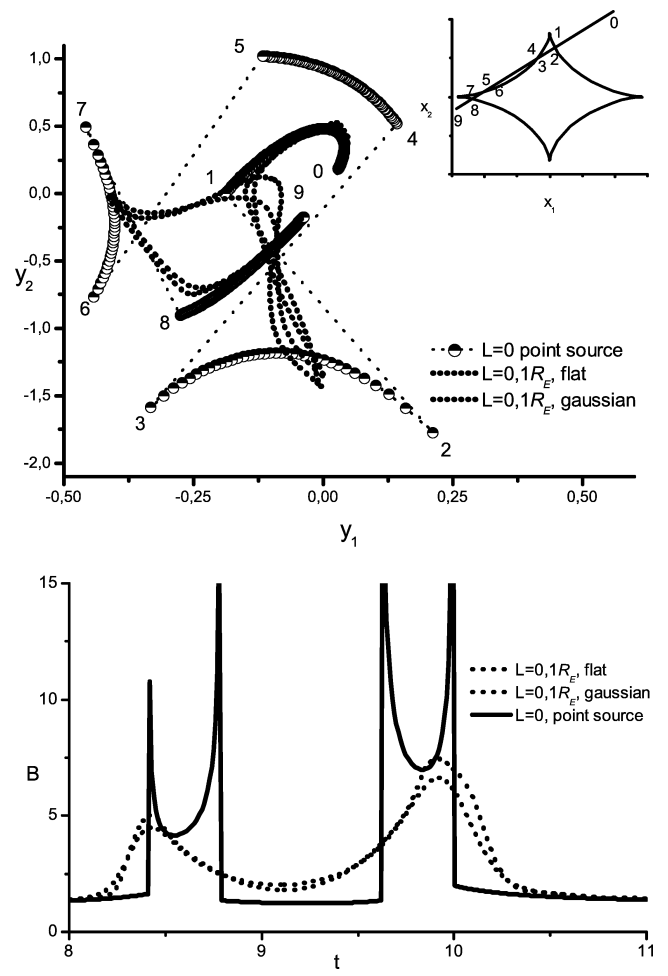

g)
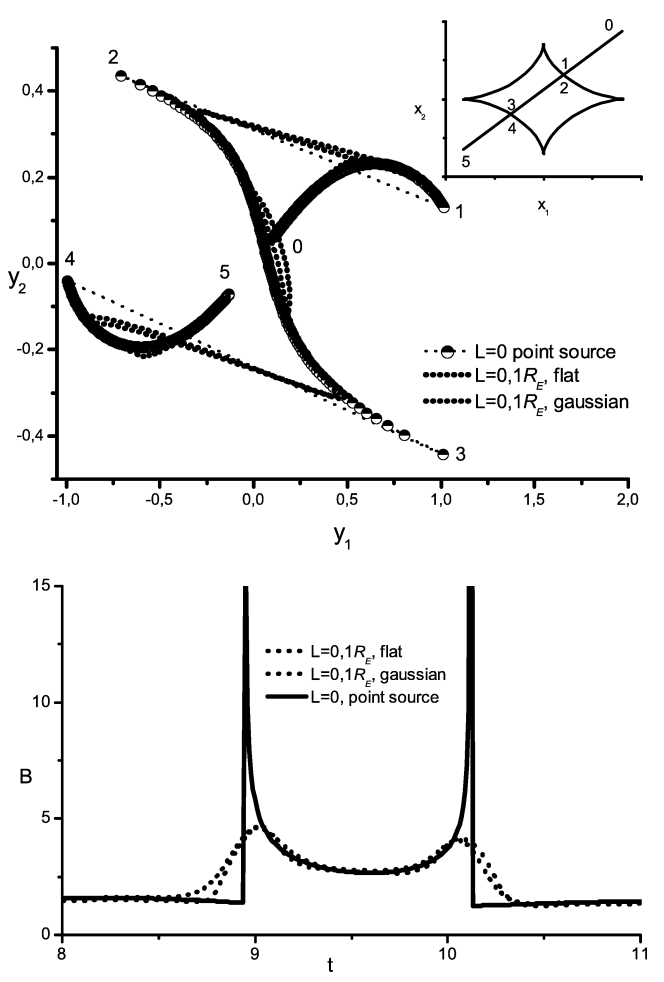

h)

Fig. 1. Trajectories of IC (upper plots) and light curves (lower plots) of a point source and of extended sources $\left(L=0.1 R_{\mathrm{E}}\right)$ with Gaussian and uniform brightness distributions. The caustic and source trajectory in the lens plane are shown in upper right-hand corner; $L$ is the source size, $\gamma$ is the shear, $p$ is the impact parameter, and $\beta$ is the angle between the $X$-axis in the source plane.

The simplest situation is when the source track is quite remote from the caustic. In this case the IC trajectory is oval-like and light curve is smooth. However, when the source track is quite close to caustic (even if it does not cross it), the IC trajectory can be more complicated. In general, it can be self-intersected three times (see Fig. 1a) and even six times (see Fig. 1b). When point source crosses the caustic, its IC suffers a jump (Figs. 1c-1h) and its total brightness becomes infinite. For a small extended source, the jumps on IC trajectory are absent due to the smoothing influence of a limited size. Other interesting situation is when the source passes near the cusp or crosses it (cf. the second brightness peak on Fig. 1d). It is important to note that when the source crosses the cusp point, the brightness becomes infinite, but no jump on IC trajectory occurs. Having the IC trajectory this allows us to distinguish the case of high amplification events with caustic crossing and when the source passes near the cusp. 
[1] P. Schneider, J. Ehlers, E. Falco, Gravitational Lenses (Springer, New York, 1992).

[2] A. F. Zakharov, Gravitational Lenses and Microlenses (Yanus, Moscow, 1997).

[3] E. Hog, I. D. Novikov, A. G. Polnarev, Astron. Astrophys. 294, 287 (1995).

[4] B. Paczynski, Astrophys. J. 494, L 23 (1998).

[5] G. F. Lewis et al., Mon. Not. R. Astron. Soc. 261, 647 (1993).
[6] H. J. Witt, Astron. J. 403, 530 (1993)

[7] H. J. Witt, Astron. Astrophys. 236, 311 (1990).

[8] V. I. Zhdanov, A. N. Alexandrov, S. A. Salata, Kinematics Phys. Stellar Bodies 16, 336 (2000).

[9] V. I. Zhdanov, S. A. Salata, Kinematics Phys. Stellar Bodies 14, 203 (1998).

[10] V. I. Zhdanov, S. A. Salata, E. V. Fedorova, Astron. Lett. 27, 562 (2001).

\title{
РУХ ЗОБРАЖЕННЯ ДЖЕРЕЛА В ЛІНЗІ ЧАНГА-РЕФСДАЛА
}

\author{
О. Федорова, В. Ж Жанов, А. Александров \\ Астрономічна обсерваторія Кийвсъкого начінального уніберситету імені Тараса Illевченка \\ вул. Обсерваторна, 3, Київ, 0З053, Украӥна
}

Досліджено форму траєкторії центра яскравости зображення віддаленого джерела випромінювання, мікролінзованого точковою масою за наявности усередненого фонового поля. Побудовано набір таких траєкторій для різних положень треку джерела щодо лінзи, для точкового джерела та, джерел із гауссівським і плоским розподілом яскравости по диску. Відносний рух джерела та лінзи вважається інерційним. 